\title{
Mammographic Diagnosis of Breast Carcinoma: An Institutional Experience
}

\author{
Sidharth,' Thapa B,' Singh Y,' Sayami P,' Khanal U² \\ 'Department of Surgery; ${ }^{2}$ Department of Radiology; Institute of Medicine, Tribhuwan University Teaching \\ Hospital, Kathmandu, Nepal
}

\begin{abstract}
Mammogram is a common diagnostic modality for breast carcinoma. Diagnostic mammogram is available at only few centers in Nepal. The aim of this study was to determine the accuracy of diagnostic mammogram in Nepalese women suffering from breast carcinoma. A retrospective analysis of the breast carcinoma was carried out in the Department of Surgery, Tribhuwan University Teaching Hospital from October 1995 to October 2007. Out of 556 patients with histologically proven breast carcinoma, 378 patients $(68 \%)$ had undergone mammography. Breast carcinoma was identified on mammography in $328(87 \%)$ cases while 50 cases $(13 \%)$ were reported as normal or benign lesions. Diagnostic mammogram had a sensitivity of $86.8 \%$, a specificity of $98.6 \%$ with a positive predictive value of $68.8 \%$ and a negative predictive value of $99.5 \%$. In mammographically missed breast carcinoma, 34\% were less than 40 years of age $(\mathrm{P}<0.05), 60 \%$ were premenopausal $(\mathrm{P}<0.05)$ and $88 \%$ patients presented with a painless lump. The study shows that the diagnostic accuracy of the mammogram is very high. However, there is a chance of missing the breast carcinoma in young and premenopausal women.
\end{abstract}

Key words: breast carcinoma, diagnostic mammogram, premenopausal women

\section{INTRODUCTION}

Diagnostic mammogram is commonly used to facilitate the diagnosis of breast cancers in women who present with symptoms or signs of the disease. The symptoms or signs may include a breast lump, pain, nipple discharge or retraction, and breast dimpling or other skin changes. A diagnostic mammographic examination usually consists of standard screening views and additional views using spot compression and/or magnification of a specific area. Although mammography is sufficient to evaluate the clinical finding, additional imaging with ultrasound, ductography or other imaging techniques may also be required.
Sensitivity and specificity have been well studied for screening mammographic studies but not for diagnostic mammography. ${ }^{1-3}$ Diagnostic mammogram may have superior performance over screening mammogram, because noticeable symptoms or clinical findings may indicate a more advanced tumor that is easier to locate and identify. Dee and Sickles found that tumors detected by diagnostic mammogram were larger than those detected by screening mammogram. ${ }^{4}$

In a country data published by WHO (1998), lung cancer accounted for $8.2 \%$ of all cancer cases, while cancer of the cervix accounted for $6.3 \%$ and breast cancer for $6 \%$ of all cancer cases in Nepal. ${ }^{5}$ Even though breast

\author{
Correspondence: \\ Dr. Sidharth \\ Department of Surgery \\ Institute of Medicine, TUTH, Kathmandu, Nepal \\ E-mail: sidd_iom@yahoo.com
}


carcinoma is one of the most common carcinoma in females, the role of mammogram has not been studied in Nepal. We evaluated the performance of diagnostic mammogram and how performance would be influenced by the characteristics of the women undergoing the diagnostic investigation.

\section{MATERIAL AND METHODS}

This is a retrospective study done in the Department of Surgery at Tribhuwan University Teaching Hospital, Kathmandu, Nepal from October 1995 to October 2007. The data of all the cases treated surgically were retrieved from the surgery and radiology departments. The records were divided into two groups, namely benign and malignant. Breast Imaging Reporting and Data System (BIRADS) I (Normal), II (Benign finding) and III (Probably benign finding; short-interval followup suggested) were called benign while IV (Suspicious abnormality; biopsy should be considered) and $\mathrm{V}$ (Highly suggestive of malignancy; appropriate action should be taken) were taken as malignant. Only histologically confirmed cases of breast carcinoma were included in the analysis.

The individual patient factors like age, symptoms, menopausal status, size of breast lump, clinical stage and hormone receptor status were retrieved for analysis. The primary performance outcomes like sensitivity, specificity, positive predictive value (PPV) and negative predictive value (NPV) of mammogram were analyzed. Statistical analysis was done by using chi-square test for variables, $\mathrm{P}<0.05$ being considered as statistically significant.

\section{RESULTS}

A total of 11,067 diagnostic mammograms were performed in TUTH in the past 12 years. Mammographically, 477 (4.4\%) were malignant (BIRADS IV-V) and 10,590 (95.6\%) were benign (BIRADS I-III). During the study period, 556 patients underwent surgery for breast carcinoma of which only $378(68 \%)$ patients had undergone mammogram. Out of 378 patients, $328(87 \%)$ were of BIRADS score IV$\mathrm{V}$ and 50 patients (13\%) of BIRADS score I-III (Table 1). Diagnostic mammogram had a sensitivity of $86.8 \%$, a specificity of $98.6 \%$, a PPV of $68.8 \%$ and a NPV of $99.5 \%$ (Table 2).

To clarify the factors for the mammographically missed $13 \%$ of breast carcinoma, the characteristics of 378 operated and histopathologically proven cases of carcinoma breast were analyzed. Individual patient factors like age, symptoms, menopausal status, size of breast lump, clinical stage and hormone receptor status were analyzed. The comparison between mammographically malignant and benign characteristics
Table 1. BIRADS score of patients who had undergone surgery

\begin{tabular}{cc}
\hline BIRADS score & Number of patients (\%) \\
\hline I & $22(5.8)$ \\
II & $25(6.6)$ \\
III & $3(0.8)$ \\
IV & $41(10.9)$ \\
V & $287(75.9)$ \\
& $378(100)$ \\
\hline
\end{tabular}

Table 2. Comparison of mammographic diagnosis with histological diagnosis

\begin{tabular}{lccc}
\hline Mammographic & \multicolumn{3}{c}{ Histological diagnosis } \\
diagnosis & Malignant & Benign & Total \\
\hline Malignant & 328 & 149 & 477 \\
Benign & 50 & 10540 & 10590 \\
Total & 378 & 10689 & 11067 \\
\hline
\end{tabular}

of women with histologically proven breast carcinoma has also been shown (Table 3 ).

In the mammographically malignant group, $19 \%$ of patients were between 20 to 39 years of age whereas in the mammographically benign group, $34 \%$ of the patients were in this age group, which was statistically significant (Table 3 ). The average age was 48.7 (range 22 - 82) years in mammographic malignant group and 43.3 (range 22 - 67) years in the mammographically benign group.

Ninety-six percent of patients in both groups presented with lump, the mean duration of which was 8 months (range two weeks to 2.9 years) in the mammographically malignant group and 9 months (range two weeks to two years) in the mammographically benign group. Sixty percent of patients were premenopausal in whom breast carcinoma was missed mammographically, whereas only $40 \%$ of patients were premenopausal in mammographically malignant cases $(P<0.05)$ (Table 3$)$.

In the mammographically benign group, $34 \%$ of patients had a tumor size of more than $5 \mathrm{~cm}$ whereas it was $28 \%$ in the mammographically malignant group. In both the groups, more than $80 \%$ of breast carcinoma was in stage II/III (Table 3). Only 95 patients had undergone immunohistochemical analysis of estrogen receptor (ER) and progesterone receptor (PR). Eighty-two patients were in the mammographically malignant group in which $37.8 \%$ (31 patients) had ER/PR positive, whereas out of 13 patients in the mammographically benign group $46.1 \%$ (6 patients) had ER/PR positive. Altogether, $38.9 \%$ histologically proven cases of breast carcinoma had ER/PR positive. 
Sidharth et al. Diagnostic Mammogram in Breast Carcinoma

Table 3. Characteristics of women with histologically proven breast carcinoma who underwent ammography

\begin{tabular}{|c|c|c|c|}
\hline Characteristics & $\begin{array}{l}\text { Malignant } \\
\text { (\%) }\end{array}$ & $\begin{array}{c}\text { Benign } \\
(\%)\end{array}$ & p-value \\
\hline \multicolumn{4}{|l|}{ Age (years) } \\
\hline $20-29$ & $6(2.0)$ & $3(6.0)$ & \multirow{5}{*}{$<0.05$} \\
\hline $30-39$ & $57(17.0)$ & $14(28.0)$ & \\
\hline $40-49$ & $113(34.0)$ & $17(34.0)$ & \\
\hline $50-59$ & $94(29.0)$ & $13(26.0)$ & \\
\hline$\geq 60$ & $58(18.0)$ & $3(6.0)$ & \\
\hline \multicolumn{4}{|l|}{ Symptoms } \\
\hline Painless lump & $278(85)$ & $44(88)$ & \multirow{5}{*}{ NS } \\
\hline Painful lump & $13(4)$ & $4(8)$ & \\
\hline $\begin{array}{l}\text { Lump + skin } \\
\text { invasion }\end{array}$ & $24(7)$ & 0 & \\
\hline Nipple discharge & $7(2)$ & $2(4)$ & \\
\hline Asymptomatic & $6(2)$ & 0 & \\
\hline \multicolumn{4}{|l|}{$\begin{array}{l}\text { Menopausal } \\
\text { status }\end{array}$} \\
\hline Pre-menopausal & $130(40)$ & $30(60)$ & \multirow[t]{2}{*}{$<0.05$} \\
\hline $\begin{array}{l}\text { Post- } \\
\text { menopausal }\end{array}$ & $198(60)$ & $20(40)$ & \\
\hline \multicolumn{4}{|l|}{ Size of lump } \\
\hline$\leq 2$ & $39(12)$ & $8(16)$ & \multirow{4}{*}{ NS } \\
\hline $2-5$ & $185(56)$ & $23(46)$ & \\
\hline$>5$ & $91(28)$ & $17(34)$ & \\
\hline No lump & $13(4)$ & $2(4)$ & \\
\hline \multicolumn{4}{|l|}{ Stage } \\
\hline 0 & $2(0.6)$ & $2(4)$ & \multirow{5}{*}{ NS } \\
\hline 1 & $25(7.6)$ & $6(12)$ & \\
\hline II & $153(46.6)$ & $25(50)$ & \\
\hline III & $141(42.4)$ & $16(32)$ & \\
\hline IV & $7(2.2)$ & $1(2)$ & \\
\hline
\end{tabular}

\section{DISCUSSION}

Diagnostic mammogram is an important tool for evaluating the patient who presents with symptoms and/or signs of breast carcinoma. However, only $68 \%$ of total breast carcinoma patients operated in our institute underwent mammography. The reason could be the cost of mammogram, technical problems, unavailability of mammogram (in the initial phase) and clinically obvious lesions (skin ulcerations). Nevertheless, in the last five years, almost all patients with breast carcinoma underwent diagnostic mammogram.
This study assessed the overall performance of diagnostic mammography. Several studies on diagnostic mammography have been performed in Europe. ${ }^{6-8}$ Duijm et al found that diagnostic mammography had a sensitivity of $92.0 \%$ and a specificity of $97.7 \%$. Eltahir et al. ${ }^{6-7}$ obtained similar results of $93.2 \%$ sensitivity and $96.7 \%$ specificity for symptomatic women. In a study by Flobbe et al. ${ }^{8}$ diagnostic mammography had a sensitivity of $89 \%$ and a specificity of $98 \%$. Our results are comparable to the above studies. A metaanalysis of screening studies showed that sensitivity ranged from $83 \%$ to $95 \%$ and specificity ranged from $93.5 \%$ to $99.1 \%$. $^{3}$ Screening sensitivity may be lower because the cancers detected are smaller than those detected with diagnostic mammography. However, the population undergoing screening is older, and average breast density may be less. Both sensitivity and specificity of screening mammography increase with age and decrease with increasing breast density. ${ }^{9-12}$ We found similar results with diagnostic mammography.

A significant number of patients with breast carcinoma in the younger and premenopausal group were missed by diagnostic mammogram. This may be attributed to dense breast tissue. In younger patients with dense breast, additional imaging with ultrasonography is helpful. The diagnostic accuracy for carcinomas of the breast appears to improve when mammography is combined with ultrasonogram even in cases that reveal no evidence of microcalcification or other abnormalities $^{13}$. However, in our study, all patients were evaluated by mammography not in combination with ultrasound. Symptoms, size of lump and stage of carcinoma were not significant in our study.

Our previous study showed ER/PR positivity rate ranging from 11 to $15 \%$, but in the present study it was $38.9 \% .^{14}$ This could be due to the less number of cases in the previous study. However, hormone receptor status was not associated with mammographic diagnosis of breast carcinoma. Other possible causes for missed breast carcinoma include dense parenchyma obscuring a lesion, poor positioning or technique, perception error, incorrect interpretation of a suspect finding, inexperience of radiologist, subtle features of malignancy and slow growth of a lesion ${ }^{15}$.

\section{CONCLUSION}

Diagnostic mammogram has become an essential part of breast carcinoma management in Nepal. The accuracy of the detection of breast carcinoma by mammogram is very high. However, there is a chance of missing the breast carcinoma in young and premenopausal women. 


\section{REFERENCES}

1. Rosenberg RD, Lando JF, Hunt WC, Darling RR, Williamson MR, Linver MN, etal. The New Mexico Mammography Project. Screening mammography performance in Albuquerque, New Mexico, 1991 to 1993. Cancer 1996 Oct 15;78(8):1731-9.

2. Poplack SP, Tosteson AN, Grove MR, Wells WA, Carney PA. Mammography in 53,803 women from the New Hampshire mammography network. Radiology 2000 Dec;217(3):832-40.

3. Mushlin AI, Kouides RW, Shapiro DE. Estimating the accuracy of screening mammography: a meta-analysis. Am J Prev Med 1998 Feb;14(2):143-53.

4. Dee KE, Sickles EA. Medical audit of diagnostic mammography examinations: comparison with screening outcomes obtained concurrently. AJR Am J Roentgenol. 2001 Mar;176(3):729-33.

5. World Health Organization. Disease specific NCD morbidity and mortality profile [Online]. 1998 [cited 2008 Feb 10]; [8 5 screens]. Available from: URL:www.searo.who.int/ LinkFiles/NCD_InforBase_disease-specific.pdf

6. Duijm LE, Guit GL, Zaat JO, Koomen AR, Willebrand D. Sensitivity, specificity and predictive values of breast imaging in the detection of cancer. Br J Cancer 1997;76(3):377-81.

7. Eltahir A, Jibril JA, Squair J, Heys SD, Ah-See AK, Needham $\mathrm{G}$, et al. The accuracy of "one-stop" diagnosis for 1,110 patients presenting to a symptomatic breast clinic J R Coll Surg Edinb. 1999 Aug;44(4):226-30.

8. Flobbe K, van der Linden ES, Kessels AG, van Engelshoven JM. Diagnostic value of radiological breast imaging in a nonscreening population. Int J Cancer 2001 May 15;92(4):616-8
9. Kerlikowske K, Grady D, Barclay J, Sickles EA, Ernster V. Effect of age, breast density, and family history on the sensitivity of first screening mammography. JAMA $1996 \mathrm{Jul}$ 3;276(1):33-8.

10. Laya MB, Larson EB, Taplin SH, White E. Effect of estrogen replacement therapy on the specificity and sensitivity of screening mammography. J Natl Cancer Inst 1996 May 15;88(10):643-9.

11. Lehman CD, White E, Peacock S, et al. Effect of age and breast density on screening mammograms with false-positive findings. AJR Am J Roentgenol 1999;173:1651-5.

12. Porter PL, El-Bastawissi AY, Mandelson MT, Lin MG, Khalid N, Watney EA, et al. Breast tumor characteristics as predictors of mammographic detection: comparison of interval- and screen-detected cancers. J Natl Cancer Inst 1999 Dec 1;91(23):2020-8

13. Prasad SN, Houserkova D. A comparison of mammography and ultrasonography in the evaluation of breast masses. Biomed Pap Med Fac Univ Palacky Olomouc Czech Repub 2007 Dec;151(2):315-22

14. Singh $Y$, Sayami $P$, Sayami G, Nakagawa H, Koreeda T, Hatano $\mathrm{T}$, et al. Nepalese breast cancer in relation to reproductive factors: comparison between Nepalese and Japanese cases. Anticancer Res 2002 Jan-Feb;22(1A):319-23.

15. Majid AS, de Paredes ES, Doherty RD, Sharma NR, Salvador $X$. Missed breast carcinoma: pitfalls and pearls. Radiographics 2003 Jul-Aug;23(4):881-95. 